\title{
Mechanical properties of hybrid glass/ kenaf fibre-reinforced epoxy composite with matrix modification using liquid epoxidised natural rubber
}

\author{
Yusri H Muhammad', Sahrim Ahmad', Mimi A Abu Bakar², \\ Abdullah A Mamun ${ }^{3}$ and Hans P Heim ${ }^{3}$
}

\begin{abstract}
The hybridisation of natural fibre with glass fibre provides a method to improve the mechanical properties instead of using the natural fibres alone. This research is focused on the hybridisation of glass/kenaf fibre with the addition of liquid epoxidised natural rubber to enhance the desired mechanical properties of the composite by reducing the synthetic fibre usage and encourage the natural fibre consumption. Liquid epoxidised natural rubber was added to the epoxy matrix in order to improve its mechanical properties whilst E-glass fibre and kenaf bast fibre were used as the reinforcement in the composite. Liquid epoxidised natural rubber (3\%) was added as a toughening agent. Two types of kenaf fibre were prepared - untreated and treated with $6 \% \mathrm{NaOH}$ - whilst the glass fibre was treated using a silane coupling agent. The flexural test, Izod impact test, environmental stress cracking resistance analysis and scanning electron microscopy analysis were performed to determine the effect of fibre treatment and liquid epoxidised natural rubber addition on the mechanical properties of the hybrid fibre-reinforced composite. It was found that the treatment and the addition of liquid epoxidised natural rubber contribute to the increment of the impact strength by $40 \%$ whilst the flexural properties recorded a $13 \%$ and $15 \%$ increment for both flexural strength and flexural modulus, respectively. The environmental stress cracking resistance analysis showed that the composites are more affected in acid medium followed by base medium and then with the control medium (air). The addition of liquid epoxidised natural rubber seems to improve the stability of the samples in the medium initially but tends to decrease rapidly over time due to debonding of the rubber particles.
\end{abstract}

\section{Keywords}

Liquid epoxidised natural rubber, glass fibre, kenaf fibre, hybrid, epoxy, mechanical properties

\section{Introduction}

The preservation of our environment requires us to develop materials that can degrade or are biodegradable so that the materials will not remain indefinitely. Industry, especially the automotive sector, which is an enormous user of bulk materials, would like a halfway house of reasonably long-lived materials that nevertheless degrade back into the environment when they are no longer needed. ${ }^{1}$ Composite reinforced plastic materials based on natural materials, which are mainly derived from plant sources, show promise in providing this, and may turn out to be one of the material revolutions of this century. Natural fibre composites
'School of Applied Physics, Faculty of Science and Technology, Universiti Kebangsaan Malaysia, Selangor, Malaysia

${ }^{2}$ Faculty of Mechanical Engineering, University Technology MARA, Selangor, Malaysia

${ }^{3}$ Institute of Material Engineering, University of Kassel, Kassel, Germany

\section{Corresponding author:}

Yusri H Muhammad, School of Applied Physics, Faculty of Science and Technology, Universiti Kebangsaan Malaysia, 43600 Bangi, Selangor, Malaysia.

Email: yusrihelmi@ymail.com 
have low cost, tool wearing rates, production energy requirements and health and safety risks, as well as good formability and thermal insulation properties; they also exhibit no splintering function, which is ideal in some applications. ${ }^{2}$ However, the usage of materials that are fully derived from plants for production industries seems impractical because of their wellknown disadvantages, such as poor moisture resistance and low strength compared to synthetic fibre, such as glass. The answer to this uncertainty is through hybridisation. By using hybrid materials, we can reduce the usage of synthetic- and petroleum-based materials by combining them with natural-based materials. ${ }^{3}$ In this paper, Kenaf fibres have been chosen to be hybridised with glass fibres to be reinforced with the epoxy composite system. Epoxy resins are considered to be one of the most important classes of thermosetting polymers. With the reinforcement of glass fibres, epoxy resins are extensively used in many applications including aerospace, automobiles and for other engineering purposes. ${ }^{4}$ The principal advantages of glass fibre are low cost, high tensile strength, high chemical resistance and excellent insulating properties. Glass fibre-reinforced composites can only perform well when the stress can be transferred efficiently across the interphase between the fibres and the matrix. In order to improve fibre wettability or to enhance the affinity between the fibre and the matrix, modification of the fibre surface can be done by treating the fibre with silane coupling agents. ${ }^{5}$ Kenaf (Hibiscus cannabinus, L. family Malvaceae) is an economically inexpensive herbaceous annual plant that can be grown under a wide range of weather conditions. Kenaf fibres have excellent characteristics compared to other natural fibres, such as long fibre, small diameter and high interfacial adhesion to the matrix. ${ }^{6}$ It was found that alkaline treatment using $6 \% \mathrm{NaOH}$ solution was effective to improve the compatibility between lignocellulosic fibres and polymer matrices. Alkaline treatment involves immersing the fibres in $\mathrm{NaOH}$ for a period of time. It is believed to work by increasing the surface roughness of the fibres, which improves the mechanical bonding between the fibres and the matrix. $^{7}$ The main disadvantage of epoxy is its high brittleness. Therefore, modifying epoxy resins has attracted intense research interest. The main issue when it comes to modifying the brittle nature of epoxy is to maintain its good mechanical and thermal properties while increasing its toughness. ${ }^{8}$ One of the methods used by many researchers is by the addition of a rubbery content into the uncured epoxy resins. According to Phinyocheep et al., ${ }^{9}$ the mechanical properties of polyethylene terephthalate can be improved by the addition of natural rubber, while Abu Bakar et al. ${ }^{10}$ and Tan et al. ${ }^{11}$ use liquid epoxidised natural rubber (LENR) to improve the mechanical properties of epoxy composite. In this report, LENR was used as the toughening agent for the epoxy matrix. Epoxidised natural rubber is a derivative from the chemical modification of natural rubber, which is derived from the partial epoxidation of the natural rubber molecule, resulting in a new type of elastomer. LENR exhibits unique physical and chemical properties such as elasticity, stickiness and resilience. ${ }^{12}$ These property improvements result in greater flexibility and toughness of the composite samples.

\section{Materials and method}

\section{Material}

The epoxidised natural rubber was obtained from the Malaysian Rubber Board. The degree of epoxidation is $50 \mathrm{~mol} \%$ (ENR-50). The matrix used was an epoxy with the commercial name of Epikote 828 and Epicure d230 (amine), which was purchased from Lapto (M) Ltd. The reinforcement used was glass fibre type E, which was $6 \mathrm{~mm}$ long and $13 \mu \mathrm{m}$ in diameter, obtained from Eurochem (M) Ltd. The glass fibre surfaces were treated using a silane coupling agent. The amount of silane used was about $2 \mathrm{wt} \%$ with respect to the amount of glass fibres. The surface treatment was carried out in a slurry mixture of required compositions where the solvent was hydrochloric acid $(\mathrm{HCl})$. The $\mathrm{pH}$ of the mixture was controlled in the range of 4-5. The slurry was left at room temperature for $24 \mathrm{~h}$ in order to remove the $\mathrm{HCl}$. Then the glass fibres were put in an oven at $60^{\circ} \mathrm{C}$ for $3 \mathrm{~h}$ and then kept at room temperature. Another reinforcement used in this epoxy composite system was kenaf fibres that were obtained from Symphony Advance (M) Ltd. The kenaf fibres were sieved to obtain the target sizes of $125-355 \mu \mathrm{m}$ and treated with $6 \% \mathrm{NaOH}$ solution for $24 \mathrm{~h}$. The fibres were washed and dried in an oven at $40^{\circ} \mathrm{C}$ for $24 \mathrm{~h}$ to make sure no moisture was left in the kenaf.

\section{Preparation of LENR}

ENR of $1000 \mathrm{~g}$ was cut using a knife and dried under sunlight. Then $0.2 \mathrm{~g}$ blue methylene, $0.26 \mathrm{~g}$ rose bengal and toluene were mixed together with the cut and dried ENR. The mixture was left for $24 \mathrm{~h}$. After $24 \mathrm{~h}$, toluene was added to gradually melt the natural rubber chunks and stirred continuously for 10 days.

\section{Determination of rubber content in LENR}

The determination of rubber content was done after the weight of the LENR reached a constant value. A few drops of LENR were added to five pieces of plastic. 
The weight of the LENR and the plastic were recorded before and after they were dried in an oven for $24 \mathrm{~h}$ at $28^{\circ} \mathrm{C}$. The rubber content in LENR was calculated using the following equation:

$$
\frac{c-a}{b-a} \times 100=y \%
$$

where $c$ is the weight of dried LENR with plastic, $b$ is the weight of wet LENR with plastic and $a$ is the weight of the plastic. According to this equation, there is $y \%$ of rubber in $100 \mathrm{~g}$ of LENR. Therefore, $1 \mathrm{phr}$ (per hundred rubber) is equivalent to $y \% \times 100 \mathrm{~g}=x \mathrm{~g}$. For this study, $5.5 \mathrm{phr}$ LENR was used in the epoxy matrix as it was the optimum value according to a previous study. ${ }^{10}$

\section{Preparation of composite mixtures}

Five samples were prepared for each composite sample. The weight percentage of fibre used was $9 \%$, which was the optimum wt\% according to a previous study. ${ }^{13}$ The ratio of glass and kenaf used was 50:50. Epoxy-LENR mixtures were obtained by mixing the required amount of LENR with the epoxy resin. The $\mathrm{wt} \%$ of LENR used in the composites was $3 \%$. Defoamer was mixed with the epoxy to minimise the formation of bubbles in the composite. The mixture of LENR and defoamer was then thoroughly mixed with the epoxy resin for $1 \mathrm{~h}$ (single type fibres) and $2 \mathrm{~h}$ (hybrid fibres) using a mechanical stirrer. At the third minute of stirring, fibres with a specified amount of weight per cent was added to the mixture. Then, the hardener was added to the mixture in the last $15 \mathrm{~min}$ of the stirring process.

\section{Preparation of composites}

The mixture was poured into the mould $(180 \mathrm{~mm} \times 180 \mathrm{~mm} \times 3 \mathrm{~mm})$ and pressed using a hot press machine with a 7-ton metric press at $110^{\circ} \mathrm{C}$ for $15 \mathrm{~min}$. After that, the samples were cured in an oven at $80^{\circ} \mathrm{C}$ for $2 \mathrm{~h}$ and post-cured at $100^{\circ} \mathrm{C}$ for another $3 \mathrm{~h}$. For comparison, samples with single fibres reinforced with both glass and kenaf fibre were prepared following this procedure except that these samples had no LENR addition.

\section{Flexural properties characterisation}

The three-point bending tests were carried out at room temperature with a cross-head speed of $5 \mathrm{~mm} / \mathrm{min}$, span length of $80 \mathrm{~mm}$ and $1 \mathrm{~N}$ preload, according to ASTM D790. The sample dimension was $127 \times 12.7 \times 3.2 \mathrm{~mm}$. An average of at least five tests per sample was performed to report the flexural strength and flexural modulus.

\section{Izod impact test}

The impact tests were carried out with an average of five samples being tested for all percentages of glass fibre loadings according to ASTM D256. Samples with dimensions of $63 \mathrm{~mm} \times 12 \mathrm{~mm} \times 3 \mathrm{~mm}$ were prepared with a $1-\mathrm{mm}$ deep notch made in the middle edge of the sample using the Notch Davenport tool.

\section{Environmental stress cracking resistance}

Environmental stress cracking resistance (ESCR) was carried out using a Universal testing machine (Zwick 1446, Germany) according to ISO 220883:2006 with the dimensions of the samples being $10 \mathrm{~mm} \times 80 \mathrm{~mm} \times 4 \mathrm{~mm}$. The samples were bent using a three-point bending jig mounted in a chemical chamber. The load was introduced to the sample until $0.75 \%$ of elongation, which is fixed and allowed 2 min to stabilise the loading condition. The test was run in a control medium (air), $0.25 \mathrm{~N}$ sodium hydroxide $(\mathrm{NaOH})$ and $0.25 \mathrm{~N}$ hydrochloric acid $(\mathrm{HCl})$. The stress value $(\mathrm{F})$ of the samples was recorded with duration incrementally from minute 2 until 120 .

\section{Scanning electron microscope}

The morphology of the composites was investigated using a scanning electron microscope model Fesem Supra $55 \mathrm{VP}$ at an accelerating voltage of $5 \mathrm{kV}$. The fractured surface of the specimen sample was obtained from the impact and flexural testing. The impact fractured surfaces of the composite samples were coated with gold before being analysed.

\section{Results and discussion}

\section{Impact strength}

Figure 1 shows the impact strength for the epoxy composite using different types of reinforcement. For the single type fibre composite, the glass fibre reinforcement showed better impact value compared to the kenaf fibre-reinforced composite. For the treated fibres, kenaf recorded $7.6 \mathrm{~kJ} / \mathrm{m}^{2}$ compared to glass, which was $11.1 \mathrm{~kJ} / \mathrm{m}^{2}$. Hybridisation of kenaf fibres with glass fibres improved the impact value of the kenaf fibres composite by $22 \%$, which was $9.3 \mathrm{~kJ} / \mathrm{m}^{2}$. The pattern of the graph shows that the strength of the hybrid composite cannot match the strength of the glass fibre-reinforced composite neither untreated nor treated. However, the addition of LENR was found to improve the impact properties of the hybrid composite up to $10.6 \mathrm{~kJ} / \mathrm{m}^{2}$ for untreated and $13.1 \mathrm{~kJ} / \mathrm{m}^{2}$ for the treated fibres. The presence of rubber particles in the 


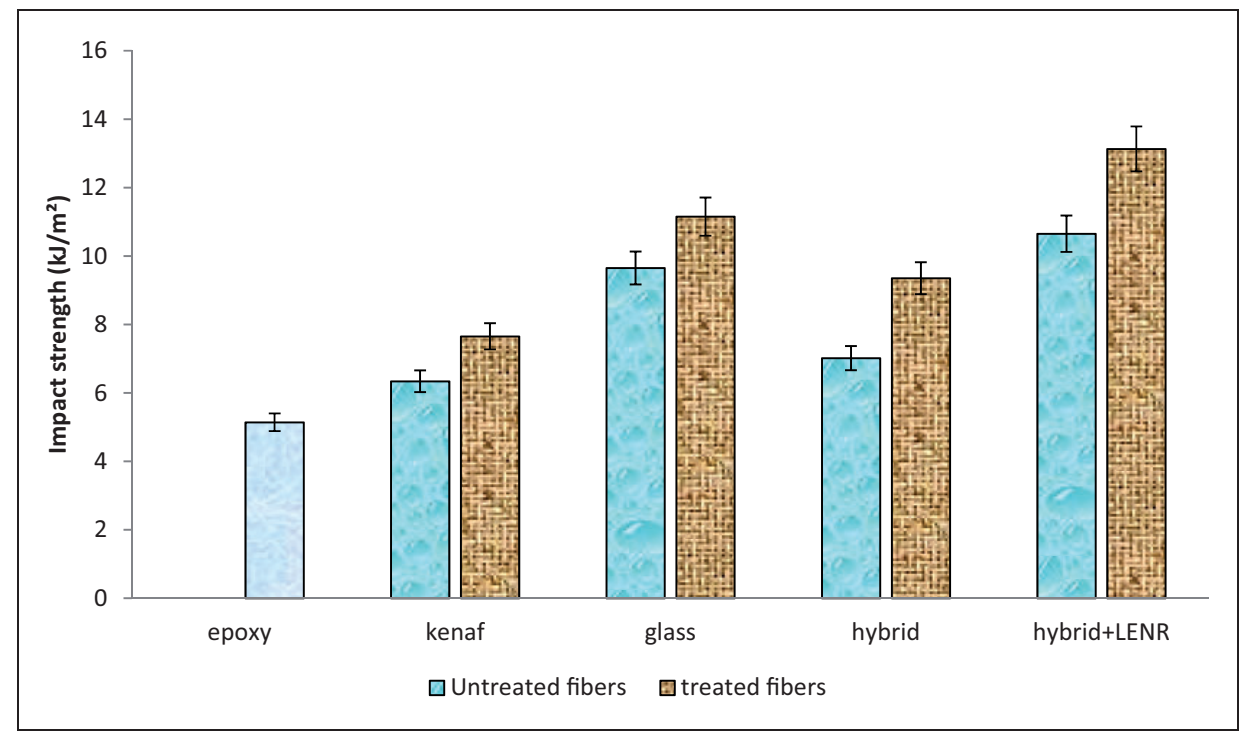

Figure I. Impact strength of fibre-reinforced epoxy composite.

epoxy plays an important role as an impact modifier in the composite. The hybrid sample with the addition of LENR was recorded to give the highest impact strength value compared to the other samples, which was $155 \%$ higher than that of the neat epoxy. This result reflected the increased strength and toughness of the composite, which was contributed from the combination properties of the hybrid fibres and the rubber particles in the LENR. It was found that the treatment of the fibres could enhance the impact property due to the better interfacial adhesion between fibres and matrix. Figure 2 shows the molecular structure of trialkoxysilane, which was used as a silane coupling agent for the glass fibre. In the presence of water, the trialkoxysilane will form the active agent of silanol in the reaction with the glass substrate. These silanol groups can undergo condensation with silanol groups naturally occurring on the glass surface to form a siloxane bond between the glass and silane coupling agent. This can result in a functionalised glass surface where the organofunctional groups can react with the epoxy matrix and produce better adhesion between the fibre and the matrix. ${ }^{14}$ The alkali treatment on kenaf fibre leads to significant differences in the fibre surface morphology. The surface of the untreated kenaf fibre was found to be covered with waxy substances and impurities. ${ }^{15}$ The treated fibres showed an improvement in the surface morphology. $\mathrm{NaOH}$ treatment removed the waxy layer and impurities from the kenaf fibres and made their surface become rougher by fibrillation as compared to that of the untreated fibres. A rougher surface could lead to a high interlock and adhesion between the fibres and the matrix, as shown in Figure 3. Moreover, the treated fibres were split into finer fibres, thus increasing the wettability of the fibres in the matrix. ${ }^{16}$ The izod impact test provided a high strain-rate test, which included the amount of energy absorbed by the composite samples during fracture. The energy absorbed can be an indicator of the given composite's toughness and acts as a tool to study the brittle-ductile transition of the material. The impact strength of the composite samples may also be influenced by many other factors including the toughness of the reinforcement, the nature of the interfacial region and the frictional work involved in pulling the fibres from the matrix. The impact strength measurement is also very sensitive to the imperfections of the samples, such as voids, bubbles, or any impurities or inclusions that may affect the results of the impact strength. ${ }^{17}$

\section{Flexural properties}

The flexural strength and flexural modulus of the composites samples are shown in Figures 4 and 5, respectively. It was shown that the flexural strength for glass fibre-reinforced composite was the highest among all the samples. The flexural strength of treated glass fibre-reinforced composites was $136 \%$ higher than that of the neat epoxy. The lowest flexural strength value was recorded by using untreated kenaf fibrereinforced composite, which was $47.9 \mathrm{MPa}$, only a $45 \%$ increment from the neat epoxy. The hybrid samples recorded $59.1 \mathrm{MPa}$ for untreated fibres and 68.1 MPa for treated fibres and the value increased 9\% when LENR was added to the hybrid composite system. The flexural strength of the hybrid composite with the addition of LENR was slightly lower than the glass fibre-reinforced epoxy composite which was $3 \%$ using the treated fibres and $2 \%$ for untreated fibres. The addition of LENR to the hybrid composite 


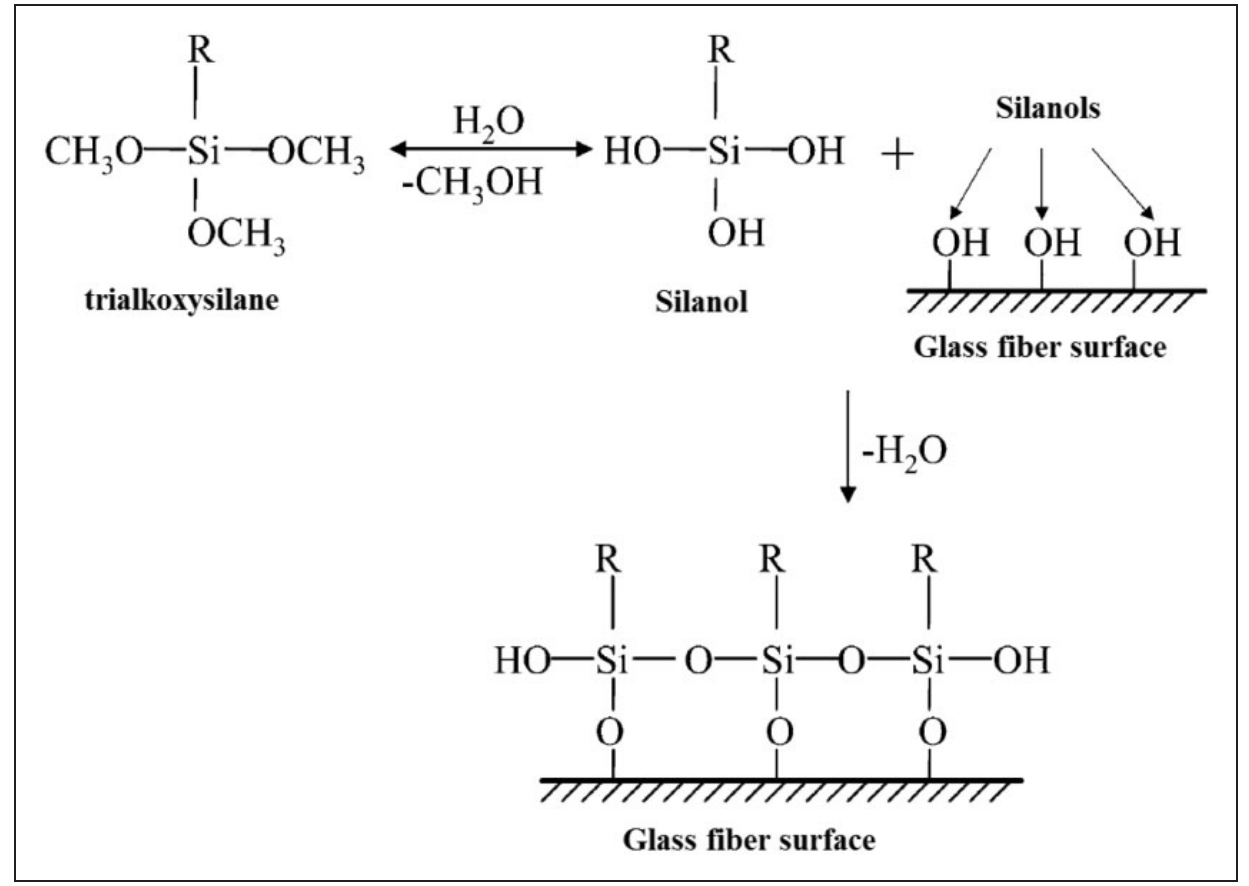

Figure 2. Silane treatment on glass fibre surface.

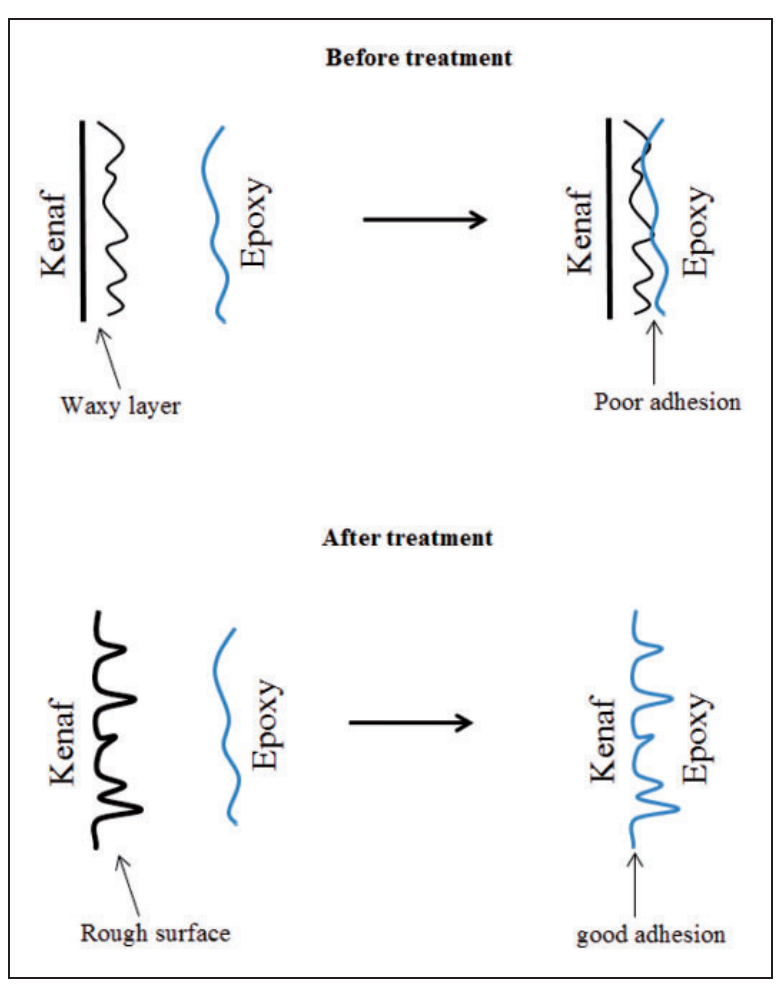

Figure 3. Effect of alkaline treatment on kenaf-epoxy surface adhesion.

tended to equal the flexural strength of the sample with the glass fibre-reinforced composite. The plasticising effect of rubber particles increased the flexibility of the composite, thus more force was needed for debonding. As shown in Figure 5, it was observed that hybridisation of kenaf fibres with glass fibres increased the flexural modulus of the composite sample by $22 \%$. The presence of the rubber particles in the matrix also increased the flexural modulus value of the samples. The maximum flexural modulus was obtained by using the treated fibres hybrid composite with LENR addition. The value was $150 \%$ higher than that for neat epoxy. This improvement was due to the toughening effect caused by the LENR modification in the matrix, thus maintaining the good energy absorbing capacity. ${ }^{18}$ The improved flexibility and toughness were mainly provided by the rubber domains formed after the addition of LENR. Furthermore, cross-linking during the reaction produced higher chain extensions, which resulted in better mechanical performance for the composite. ${ }^{19}$ This result may also be correlated with the flexibility and toughness improvement of the epoxy system. Rubber is generally well known to affect the flexural properties depending on its compatibility with the epoxy matrix, the surface area of contact, particle size, shape and content as well as the intrinsic strength of the rubber particles. ${ }^{18}$ When LENR was added to the epoxy system, the entanglement between the epoxy resin and ENR increased. This contributed to the enhancement of the flexural properties of the toughened epoxy system as it could bear the stress that was added to the sample. At the same time, it had the ability to transfer the stress applied very well and improved the flexural strength. ${ }^{20}$ It is interesting to understand how LENR toughened the composite 


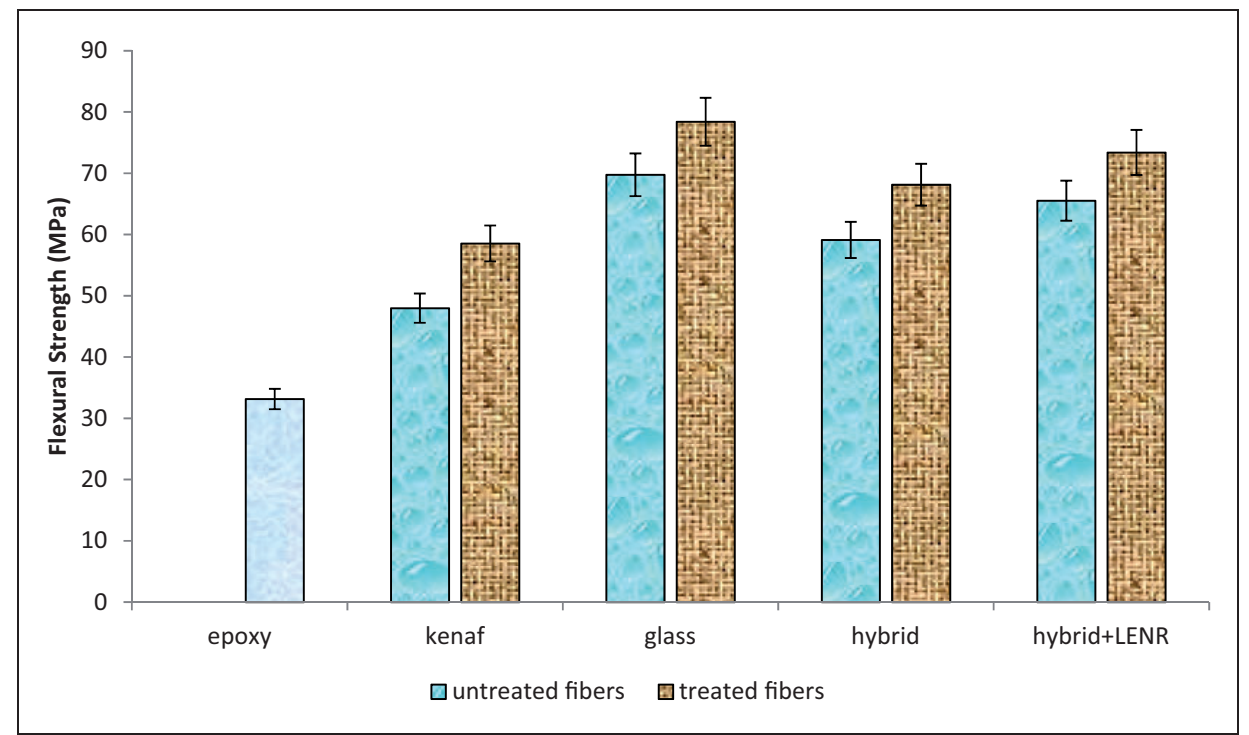

Figure 4. Flexural strength of fibre-reinforced epoxy composite.

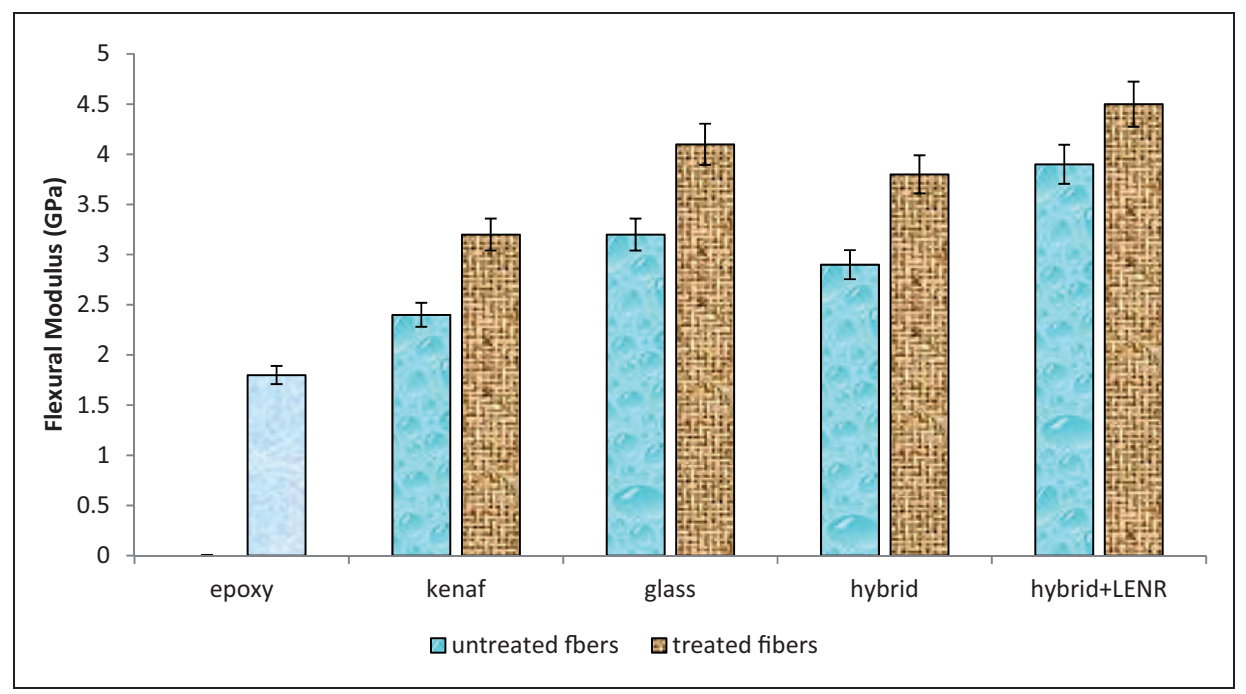

Figure 5. Flexural modulus of fibre-reinforced epoxy composite.

samples by improving the flexural properties of the composite system. The rubber particles that exist in the epoxy could bear the force applied to the composite samples. The interaction between the LENR, epoxy and curing agent was one of the reasons that contributed to the improvement of the sample's properties in addition to the better interface adhesion between the treated fibres and the matrix. ${ }^{21}$ The oxirane ring presence in both epoxy and LENR played a major role in the reaction during the curing process (Figure 6). The oxirane ring in the epoxy would open up during the curing process and produce aminoalcohol when reacting with amine (curing agent). This aminoalcohol created a bond with the oxirane ring in LENR and strengthened the interaction between the rubber particles and the epoxy. ${ }^{22}$

\section{ESCR}

Environmental stress cracking is the failure of the polymer material due to micro cracks or fractures that initiate on the surface, which are caused by the combined presence of stresses and environmental effects. The polymer's resistance towards the failure is called ESCR. Figures 7 and 8 show the stress value of composite samples in three different mediums (liquid), which are acid, base and control medium. The medium used represents the environmental aspect that can affect 


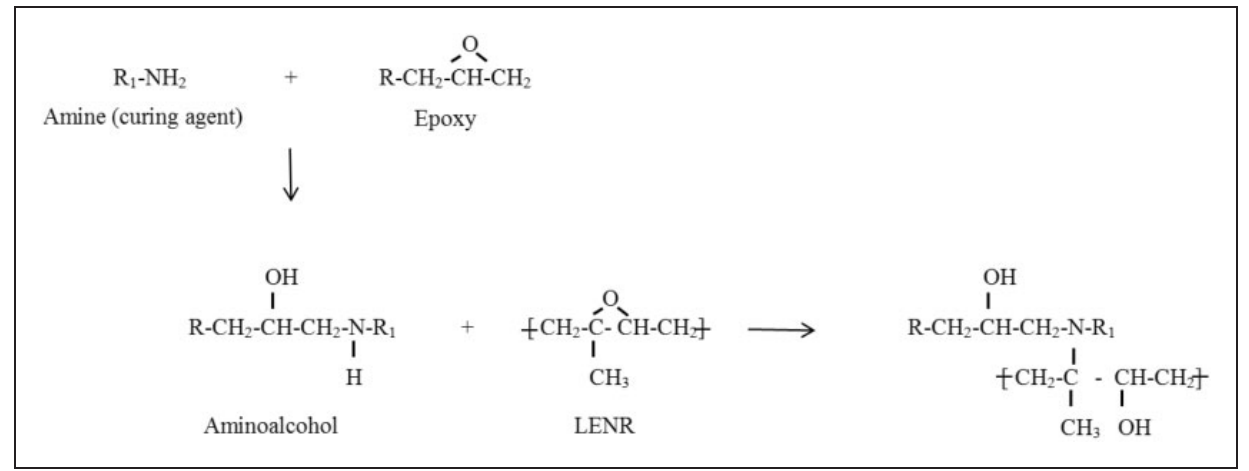

Figure 6. Reaction of oxirane ring in epoxy and LENR.

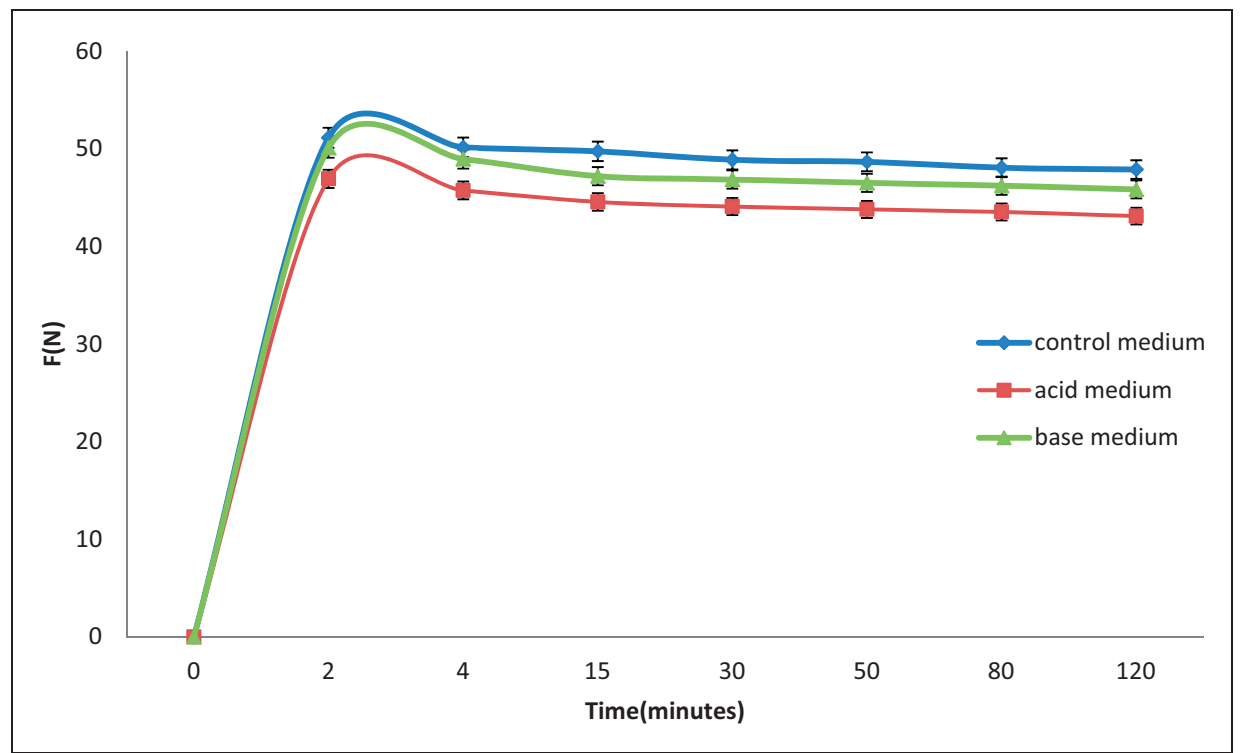

Figure 7. Comparison on ESCR effect of the hybrid kenaf/glass composites without LENR.

the premature initiation of cracking and embrittlement of the epoxy composite due to the simultaneous action of stress and strain in contact with a specific fluid. ${ }^{23}$ The stress value of the hybrid-reinforced composites in a control medium (air medium) declined over time but the reduction was found to be less than that of the composite samples in acid and the base medium. For both samples, with and without LENR addition, the stress values showed that the samples were more affected in the acid medium followed by the base medium. Figure 7 indicates that, over time, the stress value of the sample without LENR addition decreased by $9 \%$ in the acid medium followed by $6 \%$ in the base medium and $4 \%$ without medium. The addition of LENR seemed to increase the stress value of the samples at minute 2 (before the addition of mediums) but lower the stability of the samples in acid and base medium based on higher stress value reduction rate percentage after $120 \mathrm{~min}$ compared with the samples without the addition of LENR. Figure 8 shows that the stress value of the composite with LENR decreased $14 \%$ in acid medium, $10 \%$ in base medium and 5\% without medium. It can be seen that on minute 80 the stress value of the composite in the base and acid medium were nearly equal over time. This could be due to the rubber particles debonding or being pulled out from the epoxy matrix as a result of the chemical attack by the environment. ${ }^{24}$ Since micro crazes, crazes or cracks weaken the polymer exposed to chemicals, it would tend to have both a shorter time to rupture and a lower stress value, compared to those of the control specimen without medium. It seems that the stresses and environmental effects combine synergistically to accelerate the development of these micro cracks. ${ }^{24}$ 


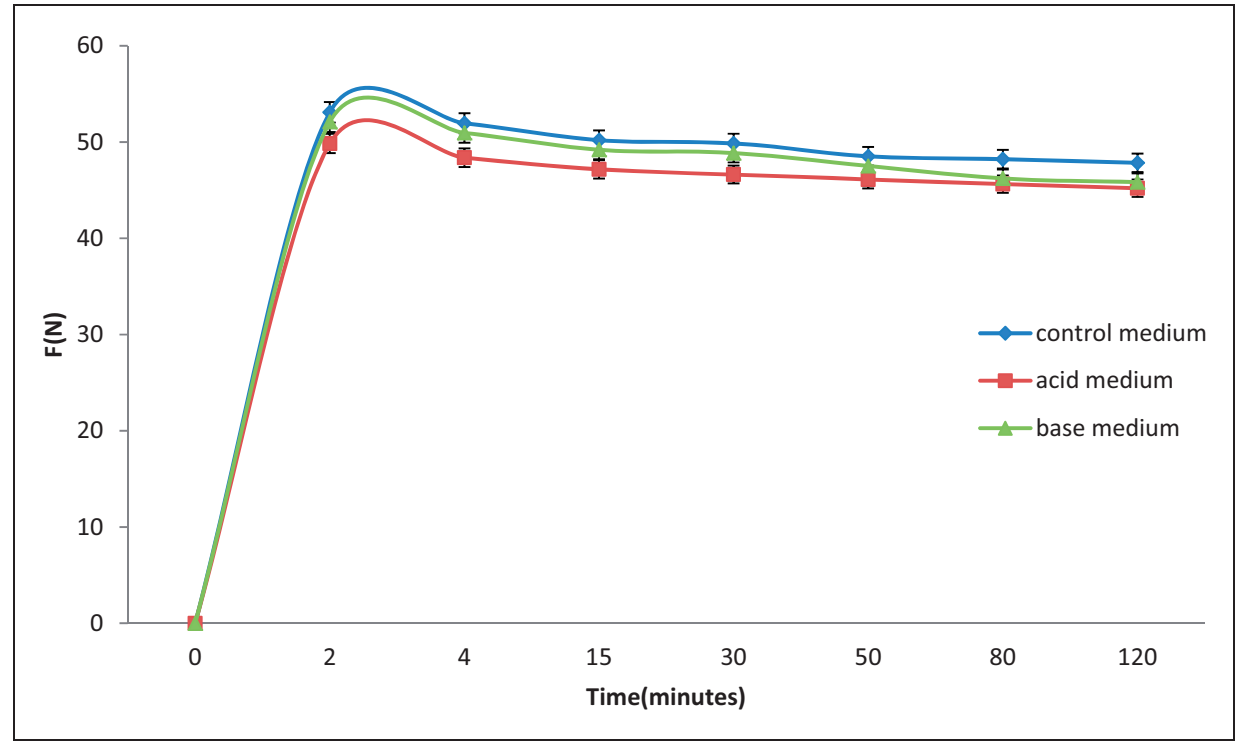

Figure 8. Comparison on ESCR effect of the hybrid kenaf/glass composites with LENR.

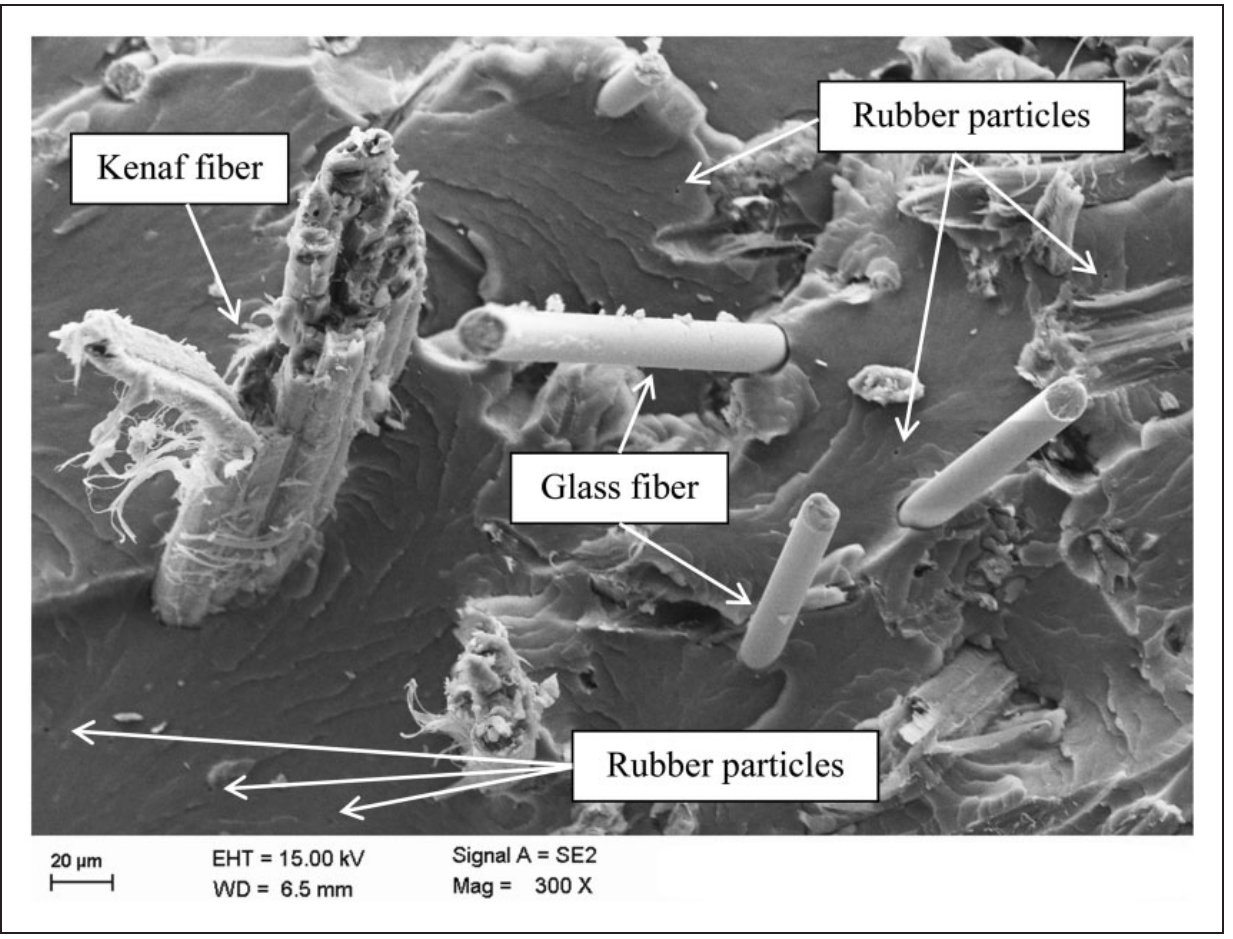

Figure 9. Kenaf and glass fibres distribution in hybrid sample.

\section{Morphological analysis}

Scanning electron microscopy analysis was used to observe the micrograph of the failure mechanism and surface adhesion between the fibres and the matrix. Figure 9 shows that the glass fibre, kenaf fibres and the rubber particles were well distributed in the epoxy

matrix for the hybrid composite system. The untreated fibre produced poor interface adhesion, and a gap can be seen between the fibre and the matrix. The untreated fibres appear to be bare, clean with no epoxy layer coating on the surface of the fibres. Figure 10 shows a clear gap between the untreated kenaf and glass fibres. Fibres that are not well bonded to the matrix will experience a lower load transfer into them and 


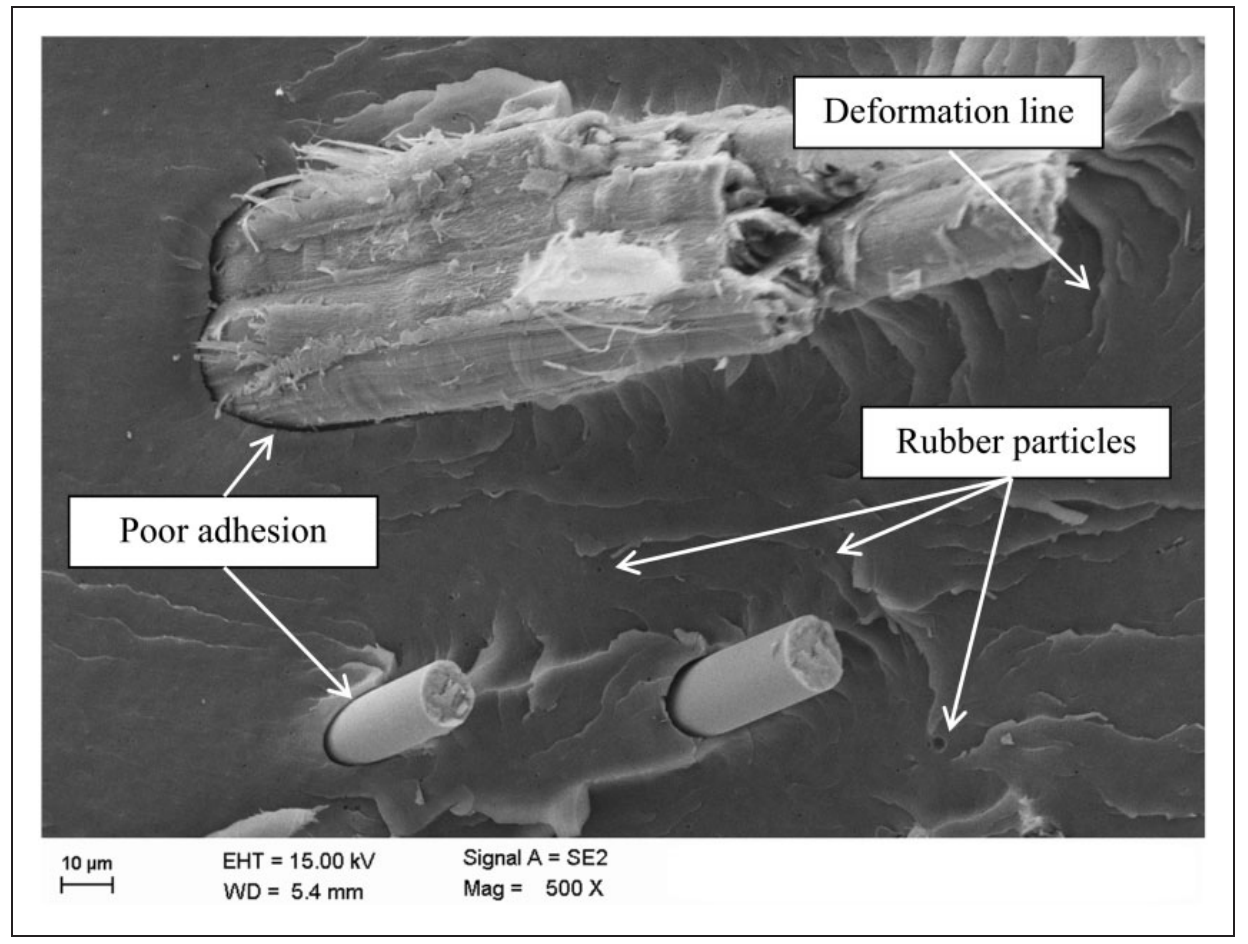

Figure I0. Surface adhesion of untreated fibres.

they will be consequently less likely to fail during fracture of the composite. This is the reason poor bonding is associated with fibre pull-out. The void-like holes observed in the figure indicate that the rubber particles are well dispersed in the epoxy matrix. ${ }^{11}$ There are different particle sizes of LENR ranging from 0.4 to $0.8 \mu \mathrm{m}$. The rubber phase appears to be a spherical particle. This spherical rubber domain induced the spinodal decomposition caused in the molecular weight of the epoxy matrix to increase during the curing process of the samples. The distorted shape of rubber domains in the epoxy resin matrices was attributed to the higher amount of plastic deformation. ${ }^{10}$ The deformation lines shown in Figure 10 were propagated through rubber domains, promoting stress transfer between the particles and epoxy matrix, and this consequently increased its toughness. ${ }^{11}$ The glass fibres treated with silane in the epoxy matrix are shown in Figure 11. The fibres seem to be coated with a sheath of epoxy and there is no gap between the fibres and the epoxy. This indicates good interfacial adhesion between them. The silane coupling agent treatment of glass fibre surface resulted in rather higher wettability, which leads to improved interfacial bonding with the epoxy matrix. This explains why the rough surface of the glass fibres had a greater adhesion with the epoxy matrix leading to an increase in the mechanical properties. ${ }^{25}$ To determine the effect of alkali treatment on the kenaf fibre and the microstructure of the composite, surface examination was carried out, as shown in Figure 12, which shows a good bonding between the kenaf fibres and epoxy with the presence of epoxy layer on the kenaf surface and no gap between the materials. This micrograph shows that strong interfacial adhesion between the kenaf fibres and epoxy matrix has become much more favourable and strong for the fibres treated with alkaline solution. The removal of the waxy layer and impurities on the kenaf surface using the treatment method leads to increased compatibility between the fibre and the matrix. Furthermore, the kenaf surface becomes rougher, which creates a good interlocking mechanism with the surface of the epoxy. These factors could be attributed to enhance the interfacial bonding and increase the incorporation between the fibres and the resin. ${ }^{19}$

\section{Conclusion}

This work studied the mechanical properties of hybrid glass/kenaf fibre-reinforced epoxy composite with the matrix modification using LENR. The results showed that the hybridisation of kenaf fibre with the glass fibre could produce better composite properties compared to the single kenaf fibre system. However, as expected, the glass fibre-reinforced epoxy composites had better mechanical properties compared to the hybrid system due to their well-known high mechanical properties. To overcome this deficiency, LENR was added in the epoxy matrix as a toughening agent to improve the mechanical properties of the hybrid composite. 


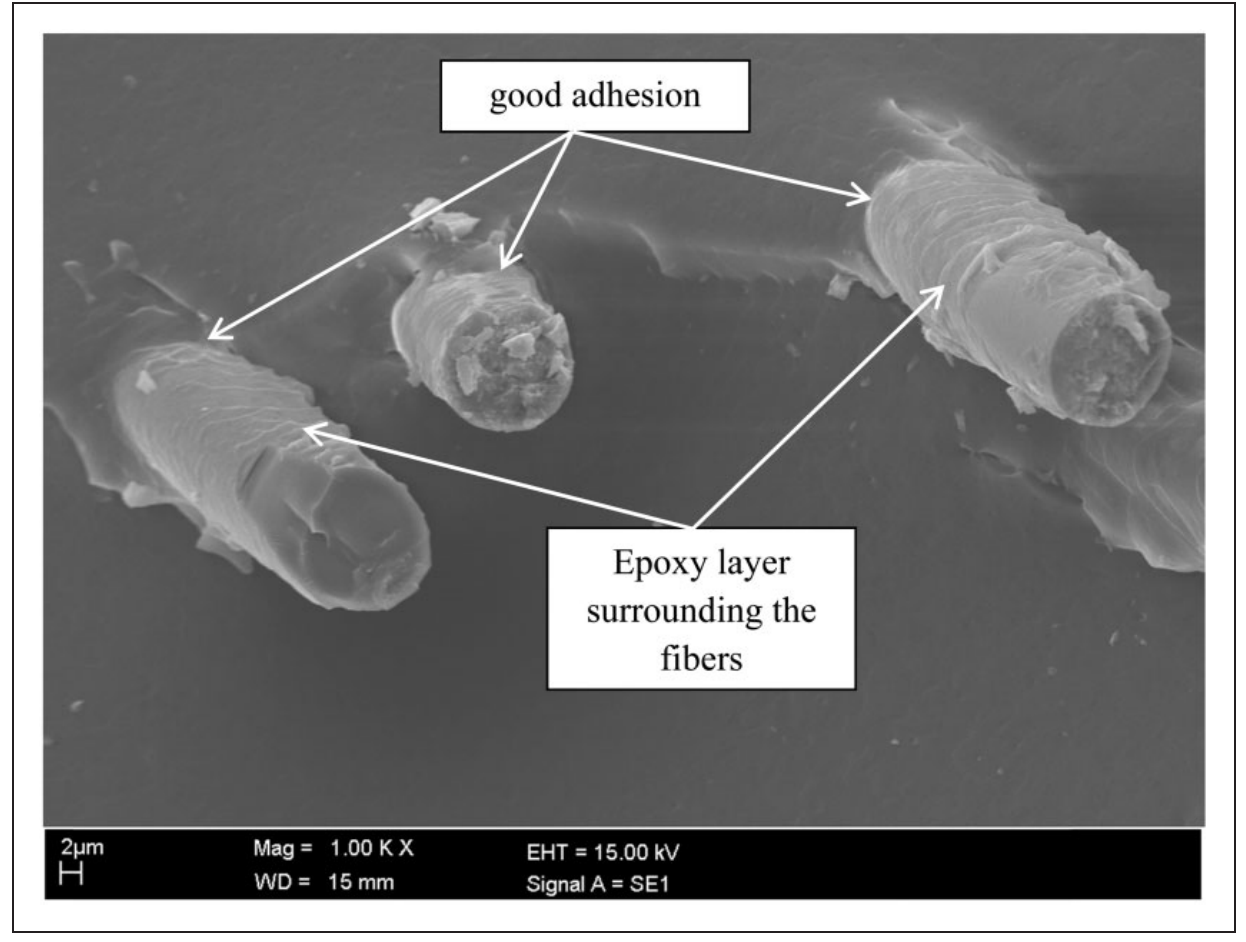

Figure II. Surface adhesion of treated glass fibres.

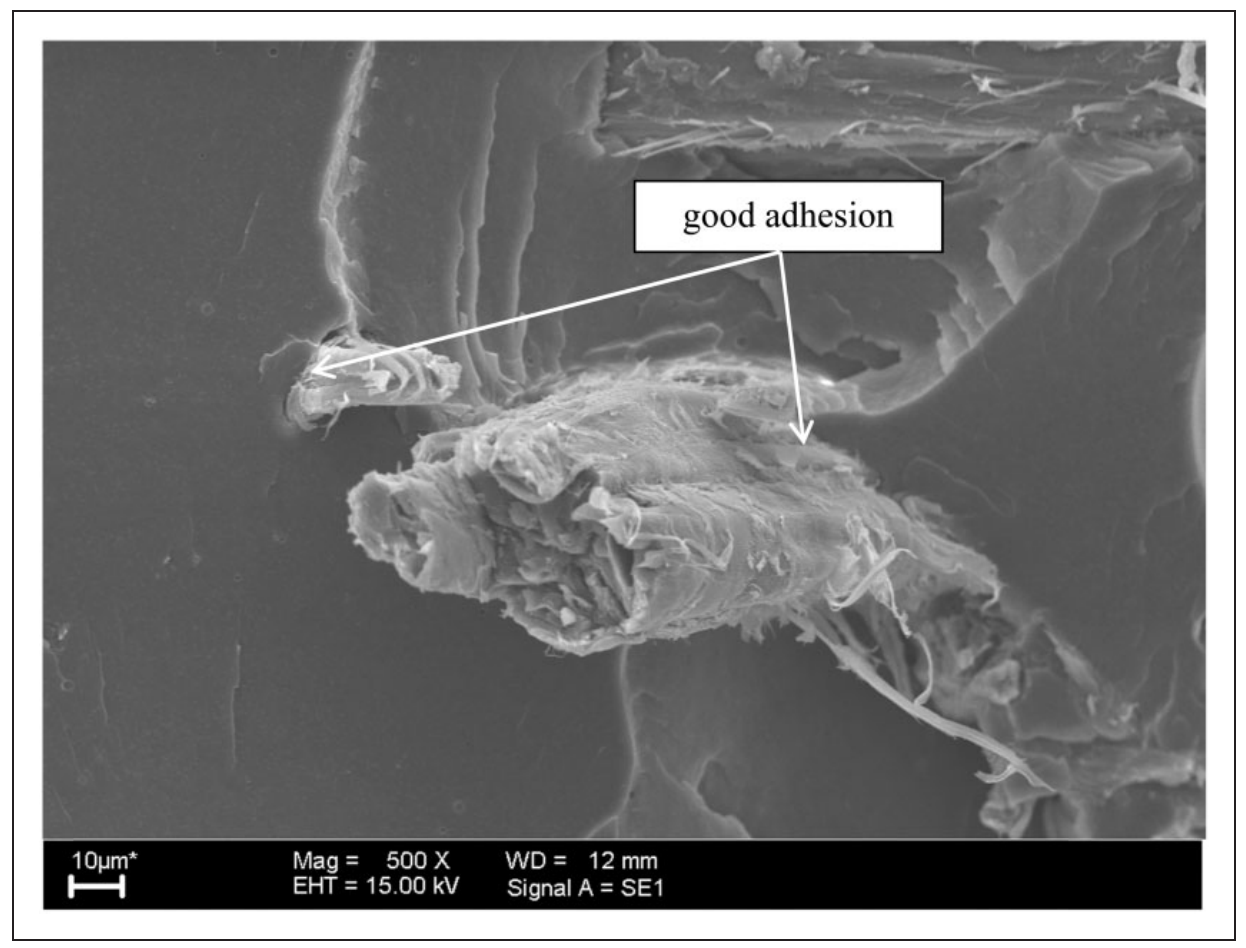

Figure 12. Surface adhesion of treated kenaf fibres.

The impact and flexural properties were found to be enhanced with the addition of LENR and the treatment of both fibres. ESCR shows that the composites are more stable with the presence of rubber particles in the epoxy. The composite samples were more affected in the acid medium followed by the base medium. The results of this study imply that the addition of LENR is a suitable method to improve the mechanical properties 
of the hybrid composite sample to even higher than the stand alone glass fibre system. Treatment of the fibres also had a major influence in providing better adhesion between the surface of the fibres and the matrix. This study implies that a hybrid of synthetic and natural fibres could be utilised in industries such as automotive or aero-space by improving the mechanical properties of the composite through matrix modification by using LENR.

\section{Conflict of interest}

None declared.

\section{Funding}

The authors wish to thank Universiti Kebangsaan Malaysia and the Ministry of Higher Education for financial assistance and for making this study a success.

\section{References}

1. Reijnders L and Huijbregts MAJ. Life cycle greenhouse gas emissions, fossil fuel demand and solar energy conversion efficiency in European bioethanol production for automotive purposes. J Cleaner Prod 2007; 15: 1806-1812.

2. Faris M and Sapuan SM. Natural fiber reinforced polymer composites in industrial applications: feasibility of date palm fibers for sustainable automotive industry. J Cleaner Prod 2014; 66: 347-354.

3. Zhang Y, Li Y, Ma H, et al. Tensile and interfacial properties of unidirectional flax/glass fiber reinforced hybrid composites. Compos Sci Technol 2013; 88: 172-177.

4. Bansemir $\mathrm{H}$ and Haider O. Fibre composite structures for space applications - recent and future developments. Cryogenics 1998; 38: 51-59.

5. Thomason JL. The interface region in glass fibre-reinforced epoxy resin composites: 1. Sample preparation, void content and interfacial strength. Composites 1996; 26: 467-475.

6. Meona MS, Othmana MF, Husaina $\mathrm{H}$, et al. Improving tensile properties of kenaf fibers treated with sodium hydroxide. Procedia Eng 2012; 41: 1587-1592.

7. Li X, Tabil LG and Panigrahi S. Chemical treatments of natural fiber for use in natural fiber-reinforced composites. J Polym Environ 2007; 15: 25-33.

8. Fombuena V, Bernardi L, Fenollar O, et al. Characterization of green composites from biobased epoxy matrices and bio-fillers derived from seashell wastes. Mater Des 2014; 57: 168-174.

9. Phinyocheep P, Saelao J and Buzaré JY. Mechanical properties, morphology and molecular characteristics of poly(ethylene terephthalate) toughened by natural rubber. Polymer 2007; 48: 5702-5712.

10. Abu Bakar MA, Ahmad S and Kuntjoro W. Mechanical and thermal properties of LENR modified epoxy composites. J Mech Eng 2011; 8: 77-89.
11. Tan SK, Ahmad S, Chia CH, et al. A comparison study of liquid natural rubber (LNR) and liquid epoxidized natural rubber (LENR) as the toughening agent for epoxy. Am J Mater Sci 2013; 3: 55-61.

12. Ruksakulpiwat Y, Sridee J, Suppakarn N, et al. Improvement of impact property of natural fiber - polypropylene composite by using natural rubber and EPDM rubber. Composites: Part B 2009; 40: 619-622.

13. Muhammad YH and Ahmad S. Mechanical and thermal properties of glass fiber-reinforced epoxy composite with matrix modification using liquid epoxidized natural rubber. J Reinf Plast Compos 2013; 32: 612-618.

14. Kaynak C, Arikana A and Tincera T. Flexibility improvement of short glass fiber reinforced epoxy by using a liquid elastomer. Polymer 2003; 44: 2433-2439.

15. Abdul Khalil HPS and Suraya NL. Anhydride modification of cultivated kenaf bast fibers: morphological, spectroscopic, and thermal studies. Bioresources 2011; 6: 1122-1135.

16. Asumani OML, Reid RG and Paskaramoorthy R. The effects of alkali-silane treatment on the tensile and flexural properties of short fibre non-woven kenaf reinforced polypropylene composites. Composites: Part A 2012; 43: 1431-1440.

17. Nuthonga $\mathrm{W}$, Uawongsuwan $\mathrm{P}$, Pivsa-Arta $\mathrm{W}$, et al. Impact property of flexible epoxy treated natural fiber reinforced PLA. Compos Energy Procedia 2013; 34: 839-847.

18. Arroyo M, López-Manchado MA, Valenti JL, et al. Morphology/behavior relationship of nanocomposites based on natural rubber/epoxidized natural rubber blends. Compos Sci Technol 2007; 67: 1330-1339.

19. Yousif BF, Shalwan A, Chin CW, et al. Flexural properties of treated and untreated kenaf/epoxy composites. Mater Des 2012; 40: 378-385.

20. Rajasekar R, Pal K, Heinrich G, et al. Development of nitrile butadiene rubber-nanoclay composites with epoxidized natural rubber as compatibilizer. Mater Des 2009; 30: 3839-3845.

21. Jayle L, Bucknall CB, Partridge IK, et al. Ternary blends of epoxy, rubber and polycarbonate: phase behaviour, mechanical properties and chemical interactions. Polymer 1996; 37: 1897-1996.

22. Yoksan R. Epoxidized natural rubber for adhesive applications. Kasetsart J (Nat Sci) 2008; 42: 325-332.

23. Amaro AM, Reis PNB, Neto MA, et al. Effects of alkaline and acid solutions on glass/epoxy composites. Polym Degrad Stab 2013; 98: 853-862.

24. Bonnia NN, Ahmad S, Zainol I, et al. Mechanical properties and environmental stress cracking resistance of rubber toughened polyester/kenaf composite. eXPRESS Polym Lett 2010; 4: 55-61.

25. Lien WF, Huang PC, Tseng SC, et al. Electroless silver plating on tetraethoxy silane-bridged fiber glass. Appl Surf Sci 2012; 258: 2246-2254. 